\title{
Comparison the Effect of Gabapentin and Theophylline on Post Spinal Headache After Cesarean Section
}

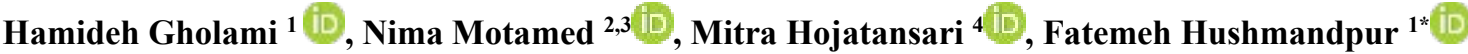 \\ 1. Dept. of Obstetrics and Gynecology, School of Medicine, Ayatollah Mousavi Hospital, Zanjan University of Medical \\ Sciences, Zanjan, Iran \\ 2. Dept. of Community Medicine, School of Medicine Zanjan University of Medical Sciences, Zanjan, Iran \\ 3. Social Determinants of Health Research Center, Zanjan University of Medical Sciences, Zanjan, Iran \\ 4. Dept. of Emergency and Critical Care Nursing, School of Nursing and Midwifery, Zanjan University of Medical \\ Sciences, Zanjan, Iran
}

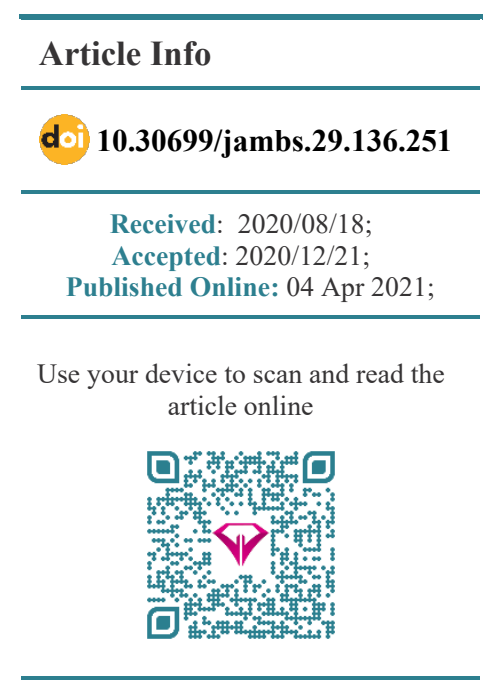

Corresponding Information: Fatemeh Hushmandpur, Dept. of Obstetrics and Gynecology, School of Medicine, Ayatollah Mousavi Hospital, Zanjan University of Medical Sciences, Zanjan, Iran

E-Mail:

fatemeh.hushmanpur61@gmail.com

\begin{abstract}
Background \& Objective: Evidence about the effect of theophylline and gabapentin on post-spinal headache is rare. Therefore, in this study, we compared the effect of gabapentin and theophylline on post-spinal headache after cesarean section.

Materials \& Methods: We conducted a double-blind randomized clinical trial on 120 pregnant women, who underwent spinal anesthesia due to cesarean section; they had experienced post-spinal headache. They were randomly assigned to the study groups, including gabapentin and theophylline groups. The gabapentin group received $400 \mathrm{mg}$ of gabapentin, every eight hours for 24 hours. The theophylline group also received $200 \mathrm{mg}$ theophylline, every eight hours for 24 hours. The visual analog scale (VAS) score was compared between the two groups before the intervention and 8,16 and 24 hours after the intervention. Statistical analysis was done using Student's t-test. P-value less than 5\% was considered as significant.
\end{abstract}

Results: There was not any significant difference between the two groups in regards of VAS score, before the intervention and 8 and 16 hours after the intervention; the significant lower VAS score was reported by the theophylline group, 24 hours after the intervention $(0.7 \pm 1.79$ vs. $2.23 \pm 2.58, P=0.014)$. Reductions in the VAS score during 8 hours (3.14 vs. 2.67$)$, 16 hours (4.7 vs. 3.47 ) and 24 hours (5.5 vs. 3.8) were compared after the intervention; it was higher in the post-intervention compared to the pre-intervention in the theophylline group.

Conclusion: The present clinical trial study showed that reduction in the VAS score was significantly higher in the theophylline group compared to the gabapentin group, only within 24 hours. Both gabapentin and theophylline were effective against post-spinal headache, but Theophylline was more effective on pain relief within 24 hours.

Keywords: Cesarean section, Gabapentin, Headache, Theophylline

\section{Introduction}

Due to the fact that general anesthesia is associated with an increased risk of death in cesarean delivery, spinal anesthesia is currently used as the preferred method for cesarean delivery (1). The odds of maternal death and postpartum infection is significantly higher in women with cesarean section (2). Other complications following cesarean delivery are infection bleeding, placenta accreta and abdominal adhesions $(3,4)$.

One of the most common complications, which is related to the cesarean section after post spinal is headache which is caused by cerebrospinal fluid leakage. The prevalence of post-spinal headache is relatively higher in obese and young pregnant women (5-8). Previous studies have demonstrated a wide prevalence range of post-spinal headache, about $1-32 \%$ and higher (9-11).

The pain is dull or fluctuating; it is more painful when standing up and it is better at the bed time. This pain is often accompanied by symptoms such as stiff neck, tinnitus, hearing loss, photophobia and nausea (12). According to the evidence, post-spinal headache has been reported in approximately $30 \%$ of the patients, who have undergone lumbar puncture $(13,14)$.

There are various treatment methods such as oral caffeine, over hydration and some medications including: 
gabapentin, pregabalin and hydrocortisone for post-spinal headache (15-19). The gold standard treatment is an epidural blood patch.

Autologous blood transfusion into the epidural space of the lumbar spine creates a clot which is particularly attached to the dura mater; it patches the perforation directly, thus, prevents cerebrospinal fluid (CSF) leakage. The volume of blood injected into the epidural space also increases CSF pressure, and therefore reduces traction in the brain and meningeal structures. Finally, it leads to the release of symptoms (20). Given that epidural blood patch is an invasive treatment method, medical therapy may be preferable (1).

Gabapentin is a structural analogue of gamma amino butyric acid; it was used as an anticonvulsant drug for the first time. This drug is now applied in diabetic neuropathy, neuropathic cancer pain and inflammatory injury $(21,22)$. Theophylline as a form of methyl xanthine, is an adenosine receptor antagonist and can decrease intracranial blood flow and venous enlargement (23).

Evidence shows that intravenous theophylline infusion is a rapid, effective, non-invasive, practical and low-cost method to treat post-spinal headache (24-26).

As mentioned above, invasive methods for post spinal headache have complications. Oral medication is difficult when the patient has nausea and vomiting; efficacious, fast-acting, useful and harmless method is desired. There are limited reports about the effect of theophylline and gabapentin on post-spinal headache. Therefore, in this study we compared the effect of gabapentin and theophylline on post-spinal headache after cesarean section in Zanjan City, Iran.

\section{Materials and Methods}

\section{2-1. Study Design}

We conducted a double-blind randomized clinical trial on 120 pregnant women (age range: 17-42 years), in Mousavi Hospital (Zanjan, Iran) from 16 October 2018. They underwent spinal anesthesia due to cesarean section. They had post-spinal headache. The patients and physicians were un-awarded to the allocated treatment group for the patients and therefore the study was designed double- blind.

We used convenience sampling method for choosing patients. Subsequently, they were randomly assigned to the study groups: Group A) Gabapentin 400 mg (Neuropentin $400 \mathrm{mg}$ Cap), each 8 hours for 24 hours, Group B) Theophylline $200 \mathrm{mg}$ (Theomex 200 mg Cap), each 8 hours for 24 hours. Balance blocked randomization was used to allocate the patients in one of the two aforementioned groups.

\section{2-2. Eligibility Criteria}

Patients with headache due to spinal anesthesia and with cesarean delivery, whose body mass index (BMI) was in the range of $20-24.9 \mathrm{Kg} / \mathrm{m}^{2}$ in the first trimester of pregnancy, were included in the study.
Patients with a history of chronic headache or migraine, hypertension, cerebral infection, asthma, hepatic disease, known allergy to gabapentin or theophylline, previous or current history of preeclampsia, stroke, sub-arachnoid hemorrhage, sinusitis, meningitis, eye problems, prior exposure to spinal anesthesia, neurological symptoms, visual analogous scale (VAS) ( no pain (score of 0 ) and pain as bad as it could be "or" worst imaginable pain (score of 10) more than eight and patients with no response to the treatments were excluded from the study. All participants in both groups were briefly described in the study; they gave written consent and accepted to participate in the study.

\section{2-3. Measurement Tool}

We used a researcher-developed checklist designed by three obstetrics and gynecology specialists affiliated to the department of obstetrics and gynecology of Zanjan University of Medical Sciences. This checklist included: Pain score at $0,8,16$ and 24 hours after the onset of pain, as well as intervention type, BMI, cesarean section number, weight, and height.

\section{2-4. Study Procedure}

The study was double-blind and the patients and researchers were un-aware of the type of medication. The included patients through balance block randomization assigned to one of the two following groups: Group A) Gabapentin $400 \mathrm{mg}$, each 8 hours, and Group B) Theophylline $200 \mathrm{mg}$, each 8 hours. Patients were taught how to use the VAS scale. Medications were given every 8 hours and the maximum dose was three doses. Before the administration of the drugs, pain was determined by VAS scale by each patient and then was recorded at 8,16 and 24 hours after the onset of pain. Metoclopramide was injected if the patient suffered from vomiting or oral intolerance.

\section{2-5. Data Analysis}

Qualitative data were summarized with frequency and percentage; the quantitative variables were described with Mean +SD. Age, anthropometric characteristics of patients, mean pain and pain reduction in pre and post intervention phases were compared between the two groups, using student's t-test. All the analyses were done using SPSS 23 (SPSS Inc., Chicago, IL., USA). P-value less than 0.05 was considered as significant.

\section{2-6. Ethical Considerations}

Ethical approval for the study was obtained by the ethical review board of Zanjan University of Medical Sciences (ZUMS) according to Helsinki declaration (Ethic code: IR.ZUMS.REC.1397.190).

\section{Results}

In the present study, 129 patients who underwent spinal anesthesia due to cesarean section and with postdural puncture headache (PDPH) were screened. Of these, five patients did not meet the inclusion criteria, and 4 patients denied to participate. Therefore, 120 
patients were evaluated in the two groups. These patients were randomly assigned to the groups (60 patients in Gabapentin group and 60 patients in Theophylline group) (Figure 1).

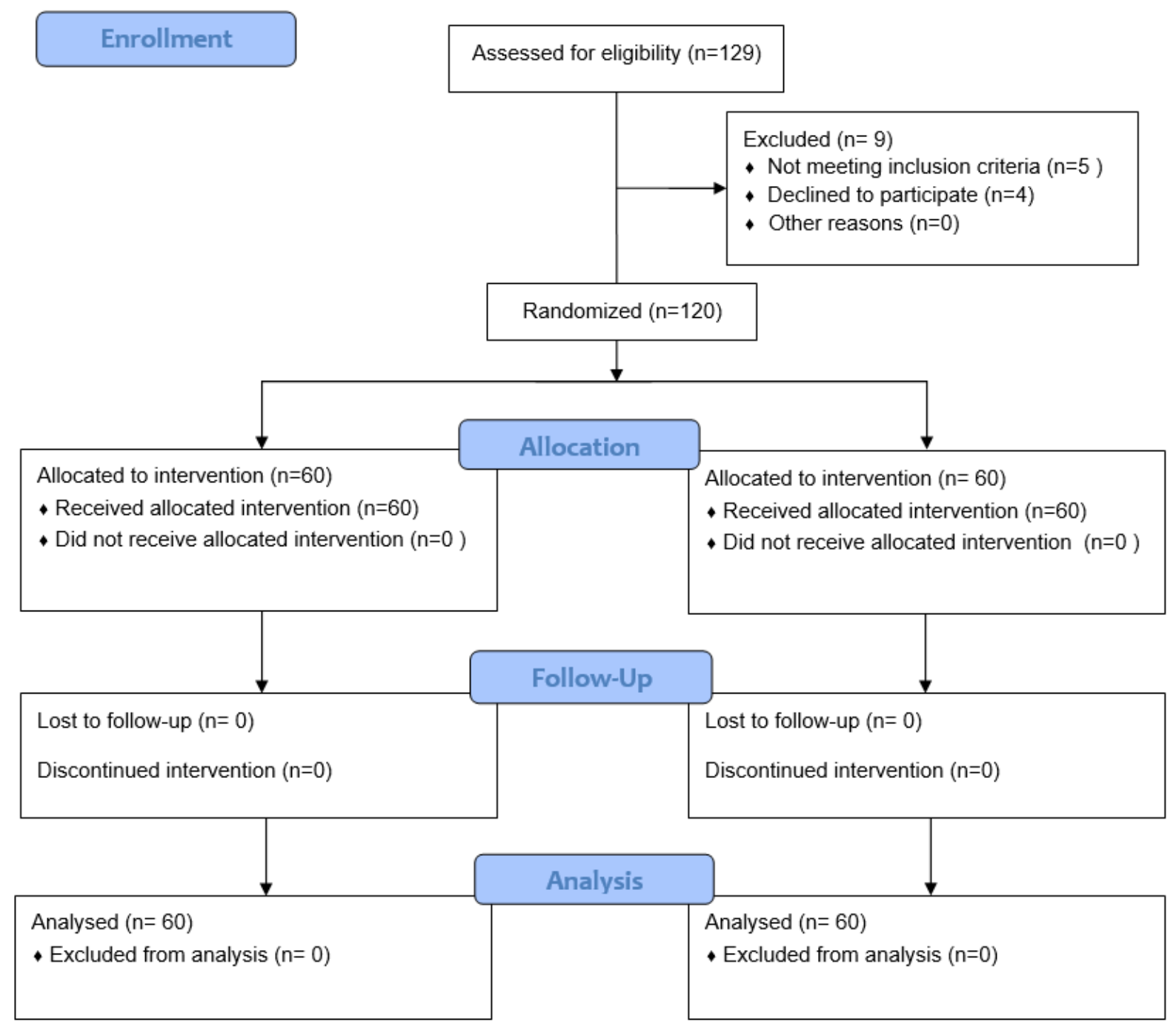

Figure 1. Flowchart on the allocation of patients to the study groups

In Table 1, we compared age and anthropometric characteristics of patients in the two investigated groups. As it was shown, both groups were homogenous in regards of baseline age, weight and BMI $(P>0.05)$, while the mean height of patients in the two groups was significantly different $(P=0.013)$.

Table 1. Age and anthropometric characteristics of patients in Theophylline and Gabapentin groups

\begin{tabular}{cccc} 
Variable & $\begin{array}{c}\text { Gabapentin group } \\
\text { Mean(SD) }\end{array}$ & $\begin{array}{c}\text { Theophylline group } \\
\text { Mean(SD) }\end{array}$ & $29 \pm 6.2$ \\
Age (Year) & $28.3 \pm 7.5$ & $1.62 \pm 0.64$ & 0.72 \\
Height (m) & $1.58 \pm 0.67$ & $79.83 \pm 15.29$ & 0.013 \\
Weight $(\mathbf{K g})$ & $75.3 \pm 12.01$ & $30.2 \pm 5.29$ \\
\hline BMI $\left(\mathbf{K g} / \mathbf{m}^{2}\right)$ & $30.1 \pm 4.7$ & 0.96 \\
\hline
\end{tabular}


In Table 2, the pain score at $0,8,16$ and 24 hours after the onset of pain has been compared between the two groups. There were not any significant differences in terms of VAS score between the two groups, in the pre- intervention phase and 8 and 16 hours after the intervention; VAS score was significantly lower in the theophylline group 24 hours after the intervention $(0.7 \pm 1.79$ vs. $2.23 \pm 2.58, P=0.014)$.

Table 2. Mean pain in the two groups receiving Theophylline and Gabapentin

\begin{tabular}{|c|c|c|c|}
\hline Pain score & $\begin{array}{l}\text { Gabapentin group } \\
\text { Mean (SD) }\end{array}$ & $\begin{array}{c}\text { Theophylline group } \\
\text { Mean (SD) }\end{array}$ & P-value \\
\hline Before intervention & $6.03 \pm 1.49$ & $6.20 \pm 1.46$ & 0.54 \\
\hline 8 hours after intervention & $3.36 \pm 2.49$ & $3.06 \pm 1.94$ & 0.61 \\
\hline 16 hours after intervention & $2.56 \pm 2.64$ & $1.5 \pm 1.88$ & 0.078 \\
\hline 24 hours after intervention & $2.23 \pm 2.58$ & $0.7 \pm 1.79$ & 0.014 \\
\hline
\end{tabular}

In Figure 2, we showed the VAS score in specific times; the VAS reduced at 8, 16 and 024 hours after the intervention compared to the pre-intervention, in the two investigated group. The reduction of VAS score at 8 (3.14 vs. 2.67$), 16$ (4.7 vs. 3.47$)$ and 24 (5.5 vs. 3.8$)$ hours after the intervention was higher compared to pre-intervention in patients who received theophylline.

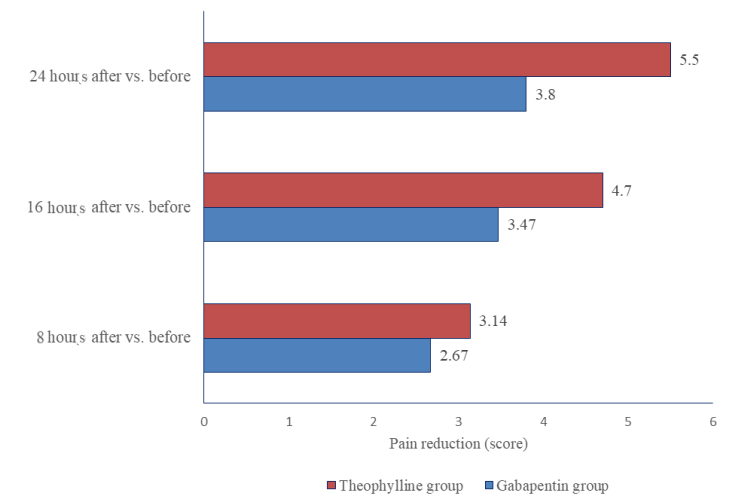

Figure 2. Mean pain reduction in the two groups receiving Theophylline and Gabapentin at 8, 16 and 24 hours after the intervention compared to the pre-intervention

\section{Discussion}

This study demonstrated that the reduction in the VAS score only within 24 hours was significantly higher in the theophylline group ( $200 \mathrm{mg}$ each 8 hours) compared to the gabapentin group $(400 \mathrm{mg}$ each 8 hours). Both gabapentin and theophylline were effective on post-spinal headache, but theophylline was more effective in pain relief within 24 hours.

Although our results suggest that both medications can successfully reduce the post-spinal headache, we did not find any studies, which compared the effects of gabapentin and theophylline on post-spinal headache after cesarean section. However, the effect of gabapentin or theophylline on post-spinal headache have been evaluated in separate studies.
In 2013, Mahmoori et al. conducted a study to evaluate the efficacy of theophylline and acetaminophen on post-spinal headache treatment. The results showed that the main VAS score was significantly lower in the patients in the theophylline group. Therefore, it seems that theophylline is a safe and effective drug for post-spinal headache. Also, no adverse effects were seen in their study (25).

Wu et al. (2016) evaluated the efficacy and safety of intravenous (IV) injection of aminophylline on postspinal headache in their study. The results showed that intravenous injection of aminophylline was an effective and safe early-stage treatment for post-spinal headache (24). These results were in line with our findings.

In consistence with our findings, in 2006, Erol et al. showed that oral administration of gabapentin in patients with post-spinal headache significantly reduces the pain score, nausea and vomiting in patients with post-dural puncture headaches (22). Beneficial effects of gabapentin on the management of patients with post-dural puncture headaches also has been shown in a study by Wagner et al. (27). Inconsistent with our results, Nofal et al. (2014) revealed that gabapentin has no effects on incidence of post-dural puncture headache, but it delays the onset of headache and reduces its severity and duration in parturient undergoing cesarean section with spinal anesthesia (28).

Theophylline is a form of methyl xanthine. This drug acts as an adenosine receptor antagonist and reduces intracranial blood flow as well as vein enlargement (23). The methyl xanthine acts via following mechanisms: (1) Interference with calcium absorption by the sarcoplasmic reticulum; (2) phosphodiesterase block activity, and (3) antagonizing the effects of adenosine. Moreover, Methyl xanthine increases CSF production through stimulating sodium-potassium pumps (29). Theophylline is also thought to manage this condition by controlling compensatory vasodilatation repairs of low CSF pressure or CSF leakage (29). 
Gabapentin is an anti-epileptic drug and a structural analogue of Gamma-Aminobutyric acid (GABA). It was approved as an effective agent to manage the neuropathic pains by Food and Drug Administration (FDA) in 2002.

Limitation of this study was the small sample size. Therefore, it is suggested to conduct similar studies with larger sample sizes using other settings and by considering the side effects of these drugs.

\section{Conclusion}

The present clinical trial study showed that reduction in the VAS score only within 24 hours was significantly higher in the theophylline group compared to the gabapentin group. Both gabapentin and theophylline were effective against post-spinal headache, but theophylline was more effective than gabapentin in pain relief within 24 hours.

\section{Acknowledgments}

This study was supported by Zanjan University of Medical Sciences. We gratefully acknowledge the kind support of the participants for their precious collaboration in this study as well as staff of Mousavi Hospital.

\section{Conflict of Interest}

The authors have no conflicts of interest to declare.

\section{References}

1. Gosch U, Hueppe M, Hallschmid M, Born J, Schmucker P, Meier T. Post-dural puncture headache in young adults: comparison of two small-gauge spinal catheters with different needle design. Br J Anaesth. 2005;94(5):657-61. [DOI:10.1093/bja/aei100]

2. Mascarello KC, Horta BL, Silveira MF. Maternal complications and cesarean section without indication: systematic review and metaanalysis. Revista de saude publica. 2017;51:105. [DOI:10.11606/S1518-8787.2017051000389]

3. Tulandi T, Agdi M, Zarei A, Miner L, Sikirica V. Adhesion development and morbidity after repeat cesarean delivery. Am J Obstet Gynecol. 2009;201(1):56. e1-. [DOI:10.1016/j.ajog.2009.04.039]

4. Marshall NE, Fu R, Guise JM. Impact of multiple cesarean deliveries on maternal morbidity: a systematic review. Am J Obstet Gynecol. 2011;205(3):262. e1-. e8. [DOI:10.1016/j.ajog.2011.06.035]
5. Ahmed S, Jayawarna C, Jude E. Post lumbar puncture headache: diagnosis and management. Postgrad Med J. 2006;82(973):713-6. [DOI:10.1136/pgmj.2006.044792]

6. Hashemi M, Akhlagh SH, Shadegan SH, et al. The impact of increased body mass index on the incidence and severity of post-spinal headache after cesarean section. J Res Med Dent Sci. 2019;7(2):1-5.

7. Bezov D, Lipton RB, Ashina S. Post-dural puncture headache: part I diagnosis, epidemiology, etiology, and pathophysiology. Headache: J Head Face Pain. 2010;50(7):114452. [DOI:10.1111/j.1526-4610.2010.01699.x]

8. Bezov D, Ashina S, Lipton R. Post-dural puncture headache: Part II-prevention, management, and prognosis. Headache: J Head Face Pain. 2010;50(9):1482-98. [DOI:10.1111/j.1526-4610.2010.01758.x]

9. Gisore E, Mung'ayi V, Sharif T. Incidence of post dural puncture headache following cesarean section under spinal anaesthesia atthe Aga KhanUniversityHospital, Nairobi. East Afr

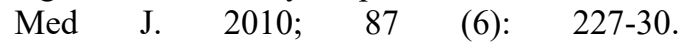
[DOI:10.4314/eamj.v87i6.63078]

10. Nuhu SI, Embu HY, Shambe I. Prevalence of postdural puncture headache among cesarean section patients in North central Nigeria. 2017.

11. Mohammed A, Ayyuba R, Salisu I, Nagoma A, Owolabi L, Ibrahim A. An analysis of postdural puncture headache in obstetric patients: A study from Kano, Nigeria. Trop J Obstet Gynaecol. 2017;34(1):16-20. [DOI:10.4103/TJOG.TJOG_61_16]

12. Amorim JA, Gomes de Barros MV, Valença MM. Post-dural (post-lumbar) puncture headache: risk factors and clinical features. Cephalalgia. 2012;32(12):916-23. [DOI:10.1177/0333102412453951]

13. Olesen J, Bes A, Kunkel R, et al. The international classification of headache disorders, (beta version). Cephalalgia. 2013;33(9):629-808. [DOI:10.1177/0333102413485658]

14. Mokri B. Headache associated with abnormalities in intracranial structure or function: low cerebrospinal-fluid-pressure headache. Wolff's Headache. 2007:513-31.

15. Huseyinoglu U, Huseyinoglu N, Hamurtekin E, Aygun H, Sulu B. Effect of pregabalin on postdural-puncture headache following spinal anesthesia and lumbar puncture. J Clin Neurosci. 2011;18(10):1365-8. [DOI:10.1016/j.jocn.2011.02.029] 
16. Ona XB, Osorio D, Cosp XB. Drug therapy for treating post-dural puncture headache. Cochrane Database Sys Rev. 2015(7).

17. Chuanjie Wu M, Yajun Lian M, Dongsheng Guan M, et al. A multicenter clinical study on treating post-dural puncture headache with an intravenous injection of aminophylline. Pain Physician. 2016;19:E761-E5.

18. Wu C, Guan D, Ren M, et al. Aminophylline for treatment of postdural puncture headache: A randomized clinical trial. Neurol. 2018;90(17):e1523-e9. [DOI:10.1212/WNL.0000000000005351]

19. Vahabi S, Nadri S, Izad F. The effects of gabapentin on severity of post spinal anesthesia headache. Pakistan J Pharmaceut Sci. 2014;27(5).

20. Safa-Tisseront V, Thormann F, Malassiné $P$, et al. Effectiveness of epidural blood patch in the management of post-dural puncture headache. J Am Soc Anesthesiol. 2001;95(2):334-9. [DOI:10.1097/00000542-200108000-00012]

21. Patel S, Naeem S, Kesingland A, et al. The effects of GABAB agonists and gabapentin on mechanical hyperalgesia in models of neuropathic and inflammatory pain in the rat. Pain. 2001;90(3):217-26. [DOI:10.1016/S03043959(00)00404-8]

22. Erol DD. The effect of oral gabapentin on postdural puncture headache. Acute Pain. 2006;8(4):169-73. [DOI:10.1016/j.acpain.2006.08.042]

23. Ibayashi S, Ngai AC, Meno JR, Winn HR. The effects of dipyridamole and theophylline on rat pial vessels during hypocarbia. J Cereb Blood Flow Metab. 1988;8(6):829-33. [DOI:10.1038/jcbfm.1988.139]
24. Ergün U, Ünal-Artık HA, Inan LE, Yoldaş T. Intravenous theophylline rapidly decreases postlumbar puncture headaches. Acta Neurologica Belgica. 2016;116(3):337-9.

[DOI:10.1007/s13760-015-0562-5]

25. Mahoori A, Hassani E, Noroozinia H, Javaheri N, Hatami S. Theophylline versus acetaminophen in the treatment of post-dural puncture headache (PDPH). Middle East J Anesthesiol. 2013;22(3):289-92.

26. Ergün U, Say B, Ozer G, et al. Intravenous theophylline decreases post-dural puncture headaches. J Clin Neurosci. 2008;15(10):11024. [DOI:10.1016/i.jocn.2007.11.001]

27. Wagner Y, Storr F, Cope S. Gabapentin in the treatment of post-dural puncture headache: a case series. Anaesth Intens Care. 2012;40(4):714-8. [DOI:10.1177/0310057X1204000420]

28. Nofal WH, Mahmoud MS, Abd Al Alim AA. Does preoperative gabapentin affects the characteristics of post-dural puncture headache in parturients undergoing cesarean section with spinal anesthesia? Saudi J Anaesth. 2014;8(3):359. [DOI:10.4103/1658354X.136433]

29. Choi A, Laurito CE, Cunningham FE. Pharmacologic management of postdural puncture headache. Ann Pharmacother. 1996;30(7-8):831-9. [DOI:10.1177/106002809603000722]

\section{How to Cite This Article:}

Gholami H, Motamed N, Hojatansari M, Hushmandpur F. Comparison the Effect of Gabapentin and Theophylline on Post Spinal Headache After Cesarean Section. J Adv Med Biomed Res. 2021; 29 (136) :251256

\section{Download citation:}

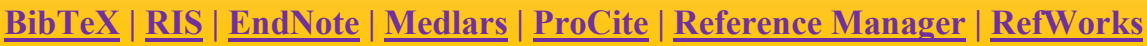

\section{Send citation to:}

(3) Mendeley 2 Zotero ; RefWorks RefWorks 